\title{
The teaching of medical ethics in the Federal Republic of Germany
}

\author{
Eduard Seidler Institute for the History of Medicine, University of Freiburg.
}

Eduard Seidler sets his discussion of the teaching of medical ethics in the Federal Republic of Germany against an historical background. Immediately after the Second World War the freshness of the memory of the 'Nuremberg Medical Trials' influenced the way in which moral dilemmas were treated in Germany.

At the present time no systematic instruction in medical ethics is provided in either undergraduate or postgraduate or continuing medical education. As a result of this, an inquiry was set up in 1977/78. Questionnaires were sent out with a view to collecting information on how subjects referring to medical ethics are treated during medical training. The inquiry showed that no special discipline can claim to be the only competent one for medical ethics, but that everyone has something to contribute.

Dr Seidler concludes by stating that basic curricula related to the problems of medical ethics would have to be developed and should be carried on continuously within the training programme.

\section{Historical aspects}

For a better understanding of the attitude which German medicine adopts when approaching problems of medical ethics, some historical facts have to be taken into consideration. We must distinguish, however, between professional ethics in particular ie the duties of the medical profession - and ethical problems concerning the decisions to be made by the individual physician, which constitute the actual 'moral dilemmas'. German medicine has approached both aspects of medical ethics independently, and has often encountered severe difficulties.

In the 19th century, professional ethics began to reveal distinctive features which emerged as a result of certain social and class-political controversies. Owing to changes which took place in the middle of the century within the professional and ethical structures of medicine, physicians were obliged on the one hand to defend their social position and professional line of conduct towards other people and, on the other, to attempt stabilisation within their own class. The appearance of highly differentiated and rather rigid rules concerning the so-called 'dignity of the profession' resulted from this attitude. These rules referred in particular to loyalty to one's colleagues, obligationss towards the law and the maintenance of professionai autonomy. For this reason, it is in this rathef special sense that the term 'medical ethics' is stilf often used and understood.

Another important historical development in Germany must also be taken into consideration: In the middle of the Igth century, the natura? sciences began to inspire medical thinking in this country to a large extent. Due to their influence $\vec{q}$ scientific ideology within medicine was encouraged,5 which focused its attention exclusively on the accomplishment of so-called objective standards $\vec{\theta}$ When searching to establish rules in conformityo with biological, psychological and physiologicab laws and apparently absolute values of the 'normalo and the 'abnormal', the influence of the naturas sciences extended far beyond medicine. Moreoverp German science eagerly seized the thoughts of Darwin and Spencer and, by discussing them and developing them further, produced a standard system which during many decades penetrated equally all intellectual and public fields. In particulag 'social Darwinism' - so problematical in its typical. German variety-caused severe consequences as far as the concepts of the good or poor 'quality' of partial races of mankind, sections of the population 3 . age groups and the healthy and infirm were concerned. These ideas initiated in a disastrous ways the demands made in the twenties of this centuryo for 'the destruction of worthless life', and were used in such a dreadful manner a little later byo National Socialism as a part of its power-politics.

We had to recall these events since, after the Second World War, there was a great deal of hesitation before public discussions on medican ethics in Germany could be started again. On the one hand German medicine had regained all the liberty necessary to deal frankly with mora! dilemmas, associated with the rapid increase in? medical knowledge, and these we faced in the same way as the rest of the world. But, on the othero

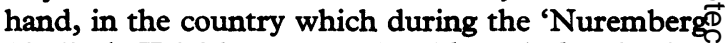
Medical Trials' was to be blamed for havingo violated the fundamental ethical concepts of medicine, conflicts regarding medical decisions continued to be treated in a more restrained wayo and involved a much greater amount of cautiousness shyness and embarrassment than was encountere产 
in other parts of the world. This is perhaps why, in treating this subject, discussions in this country have for a long time concentrated mainly on the legal and social aspects of these problems.

Because of this state of affairs, which may perhaps be more easily grasped intuitively than by thinking, it follows that the problems of medical ethics have only very recently been brought again into public discussion. This is another reason why the present study would like to be considered as a report on some of the first efforts being made to integrate ethics into medical education.

\section{Current problems of medical ethics in Germany}

The complex of issues related to medical ethics in Germany is the same as that being discussed all over the world. In theoretical discussions it is assumed that matters of medical ethics-like those of any other ethos-ought to refer to the standard applied to the outlook and actions of human society. Medical science deals with good and bad health, specific diseases, anxiety and grief. Since this is a task imposed on medicine by the patient and by society as well, any medical activity is obliged to justify itself morally, as well as in other ways.

The fundamental dilemma of medicine today and this is no different in Germany - is bound up with the claims of science to be able to benefit the life of individuals to an ever increasing degree. The challenge provoked by these claims includes both the necessity for progressive knowledge and the capacity to handle the consequences of this progressive knowledge. But one is quite aware of the fact that these consequences cannot be the subject of ethical considerations based on the standards of science. In medicine, the sciences are only there to serve, and they only form the basis of medical practice in the sense that the relevant methods are founded on 'science'. Medicine does not act on behalf of science, however, but on behalf of the sick individual. The patient trusts the physician to treat his body and mind adequately, and he expects the medical profession to show responsibility with regard to its skill and efficiency, as well as to its behaviour and attitude. This responsibility is fundamental and reaches far beyond the regions covered by any system of medical science.

This theoretical position underlying medical ethics accounts also for the concrete form taken by the practical aspects of the subject at the present time. Those disciplines whose work day after day has to cope with conflicts on ethical decisions, and in particular those connected with intensive care units within all hospital branches covering the whole range from pediatrics to geriatrics, obviously are most intimately involved. Public discussions are frequently focused on the activities of these departments; the actual problems, however, are considered and treated mainly within the individual departments themselves.

In a more systematic way the churches are dealing with medical ethics, particularly certain training centres for hospital chaplains which have been established in several university hospitals, for example in Heidelberg. Similar to them some nursing services have a long tradition of systematic instruction in professional ethics. Both fields departments of the hospital chaplain and nursing professions-developed their own training programmes, which, however, vary greatly one from another.

In the universities and university hospitals some individual personalities are developing activities and committing themselves to a scientific approach to these problems within their own field of interest. Again, these activities are particularly noticeable in the intensive care units; but specialists in forensic medicine, psychiatrists, pathologists, medical sociologists and particularly medical historians are likewise committing themselves to this task. They are joined by some competent experts in moral theology, law and philosophy. But once again we would like to point out that so far only individual approaches to integrated systematic investigations are being made.

On the other hand, students of all health professions are keenly interested in these problems. Even small programmes which have been developed within a very small scope for discussion and instruction are met with a prompt response to persevere in dealing with this subject matter. When considering these problems, students show a remarkable interest not only in the fundamental methods of finding a solution for conflicts arising from the overall decision-making process, but equally in the daily routine work of the physician, the nurse and the patient, as well as of any other persons involved.

\section{Results of inquiries into the integration of medical ethics into medical training}

In Germany no systematic instruction in medical ethics is provided, either during undergraduate training, within postgraduate training programmes or during continuing medical education. The new regulations for studies in force since 1970 with regard to all medical faculties only give a short outline on '.. the most important legal issues concerning the medical profession..., which are only taught toward the end of the training period. Since, moreover, medical training in Germany has insufficient possibilities for practical experiences, since oral bedside examinations are no longer employed, and since a total training period of six years provides hardly enough time for individual initiative in this field, there is little opportunity for 
the student to get acquainted with questions related to medical ethics. He must rely on more or less incidental references during lectures, classes or demonstration courses and on his own observations while on duty during the night, when holding an undergraduate appointment or in the course of some other casualty or general hospital employment that may reveal some of the most relevant problems to him.

In view of this situation, we started an inquiry in 1977/78 by sending questionnaires to the medical faculties in the Federal Republic of Germany. This inquiry intended to obtain a survey on how subjects referring to medical ethics are treated during medical training. Both the topics of primary concern and the programmes used for instruction were to be mentioned. We were, however, facing a particular difficulty since we did not know who was the competent expert at each university or who was to be considered as such. We therefore sent the questionnaires to the dean of each faculty asking him to distribute them.

The replies of our colleagues were, in the first instance, grouped according to the most frequently occurring specialties. The first group consisted of the traditional representatives of forensic medicine, whose instructional programme includes this aspect of medical ethics. This latter is still often considered to be identical with legal duties of the medical profession. They were, however, followed, as expected, by those clinicians who in the course of daily routine work at the hospital departments must continuously make ethical decisions. We received most replies from anaesthetists, surgeons, general practitioners and paediatricians, who were followed by human geneticists, gynaecologists, medical historians and medical psychologists. A relatively large number of individual replies from various specialists indicates that a strengthening personal commitment is developing across all the scientific disciplines.

The answers to inquiries into the particular subject matter covered by the teaching of medical ethics turned out to be as expected. In their replies all specialists pointed to those conflicts that were induced by decisions having to be made within their own fields, and they emphasised the need to convey their experiences to others by way of teaching. Consequently, paediatricians, perinatologists and gynaecologists concentrated their problems on the beginning of life, whereas surgeons, physicians and anaesthetists focused their attention upon the end of life. Psychiatrists, medical psychologists and medical sociologists, on the other hand, gave emphasis to the crises of life. Specialists in forensic medicine and medical historians obviously were equally interested in all of these problems. Many replies indicated that members of the faculties of law, theology, sociology and philosophy are likewise engaged in the search for ethical decisions and in the instruction of ethics. $\frac{1}{2}$ This may be explained by the fact that particularly those fields which are not directly related to $\overline{\bar{\gamma}}$ medicine-being frequently encouraged by the.? faculties of theology, church groups, lawyers' associations, and especially by nursing and othermedical services - are confronted with these $\frac{\bar{C}}{\sigma}$ questions at least as intensely as the actual sphere of $\overline{\bar{c}}$ medical teaching and practice itself.

The present situation of teaching ethics in the faculties of medicine varies greatly, however, Characteristic conflicts related to ethical decisions, $\vec{\circ}$ and possibilities for solving them, are mostly $\overrightarrow{\mid}$ discussed during bedside teaching. A second ${ }_{\sigma}$ possibility for teaching medical ethics is the seminars having a restricted number of students and $\overparen{D}$ concentrating on special subject matter. Only very occasionally systematic lectures are mentioned -7 which, however, cover nearly all subjects of medical ethics.

Courses in further medical education usually $\overrightarrow{\vec{c}}$ concentrate on specially chosen subjects. It seems noteworthy that the timetables of only very few ${ }^{\Phi}$ universities mention a lecture directly related to $\vec{\theta}$ medical ethics. So it is more or less incidentally that 6 the student will get acquainted with the problems, and not every faculty will give him even this opportunity.

At present, a centre for medical ethics at the Institute for the History of Medicine is established $\frac{}{D}$ at Freiburg University. For three years we have $\stackrel{2}{\Rightarrow}$ been developing an instructional programme in $\frac{0}{3}$ close co-operation with clinicians of various disciplines, schools of nursing and the department of the hospital chaplain, as well as with representatives of the faculties of law and theology. This $\underset{0}{\overrightarrow{0}}$ programme comprises continuing seminars on $\overline{-}$ fundamental and particular issues of medical 3 . ethics, lectures on varying topics, meetings with $\delta$ other disciplines and individual addresses. Also, students, nurses and other health professions are $\mathrm{O}$ given an opportunity to participate in 'Junior Balint groups', and additional attempts are made to pursue common studies. Last but not least, we teach medical ethics at the training school for $\mathrm{N}$ social workers and in schools of nursing. The $N$ research work is centred on the Institute for the $\underset{\mathrm{N}}{\mathrm{N}}$ History of Medicine which also keeps the records, 0 and this work is supported by the medical council. 0 We would like to repeat again, however, that the programme developed in Freiburg is the result of $\stackrel{?}{?}$ one of the aforementioned individual initiatives, and $T$ that it is still in an early stage.

In a prior publication we have given a detailed $\mathbb{D}$ description of the results of this inquiry. ${ }^{1}$ The $\mathbb{\mathbb { D }}$ specific situation in Germany accounts for the $O$ mainly qualitative character of the results and confirms more or less well-known facts, as stated $\frac{0}{0}$ before. It became clear that no special discipline can claim to be the only competent one for medical 
ethics, but that everyone may contribute his specific aspect and method to this field.

In order to create the conditions required, all persons providing services for patients - physicians, nurses, medical emergency services, hospitals, departments of the hospital chaplain etc. - must be trained to develop the capability of recognising, understanding and holding a moral attitude towards the problems of medical ethics. ${ }^{2}$ We would like to emphasise that these capabilities are to produce a sensitivity in the understanding of ethical conflicts, since their solutions will not be found by teaching and learning standardised facts. This is also demonstrated by the great variety of efforts which can be noticed in the replies to our inquiries.

Consequently, basic curricula related to the problems of medical ethics will have to be developed and should be carried on continuously within the training programme. Learning and experiencing ethical problems in medicine is, however, a task assigned to all persons involved. Therefore, structures for the promotion of mutual consideration of possible solutions need to be established. The colleagues who are dealing with these problems in the Federal republic of Germany realise that they are at present facing the beginning of a great and difficult task.

\section{References}

${ }^{1}$ Brand, U and Seidler, E (1978). Medizinische Ethik in der Ausbildung des Arztes. Eine Umfrage an den Hochschulen der Bundesrepublik, Österreichs und der Schweiz. Ärzteblatt Baden-Württemberg 33, 362-37r.

${ }^{2}$ Seidler, E (ed) (1979). Wörterbuch medizinischer Grundbegriffe. Eine Einführung in die Heilkunde. Freiburg: Herder. 